\title{
Tecnologia informática e matemática nos anos iniciais: analisando um processo formativo com estudantes de pedagogia e professores
}

Ana Paula Gestoso de Souza ${ }^{1}$

Cármen Lúcia Brancaglion Passos²

\begin{abstract}
Resumo
Investigam-se contribuições de um curso de extensão online que promoveu reflexões e espaços de aprendizagem relativos ao ensino de matemática e à tecnologia informática. Analisam-se o percurso percorrido pelos participantes, os conhecimentos mobilizados e suas aprendizagens. Optou-se pelo estudo de caso do curso. Tomaram-se como dados depoimentos dos participantes registrados nas atividades. Revelou-se a importância de eleger o diálogo e o trabalho com o outro como estratégias formativas conectadas por momentos de estudos sobre a articulação entre tecnologia informática e o ensino de matemática; de análise e experimentação de softwares; e de planejamento e discussão de situações de ensino.

Palavras-chave: Formação de professores; Tecnologia digital; Ensino de matemática.
\end{abstract}

Information technology and mathematics: analyzing a training process with pedagogy undergraduates and teachers

\section{Abstract}

The paper examines the contributions of an online extension that sought promoted reflections and learning spaces for the teaching of mathematics and information technology. It analyses the course taken by the participants, the knowledge mobilized and their learning. We used the testimonies of the participants, which were registered during the activities of the course, as data. It was revealed the importance of choosing dialogue and group work as training strategies, connected by moments of studies on the relation between information technology and the teaching of mathematics, software analysis and testing, as well as the analysis and planning of teaching situations.

Keywords: Teacher education; Digital technology; Teaching of mathematics.

\section{Introdução}

Neste estudo, investiga-se, sob a ótica de alunos de Pedagogia e professores dos anos iniciais, as contribuiç̧̃es de um curso de extensão universitária online que buscou promover reflexões e espaços de aprendizagem relativos ao ensino de matemática e à tecnologia informática, para o processo de aprender a ensinar matemática.

Na primeira seção deste texto, discutem-se os aportes teóricos relativos à incorporação da tecnologia digital às práticas pedagógicas e à formação docente. Em seguida, apresentam-se

\footnotetext{
${ }^{1}$ Universidade Federal de São Carlos, São Carlos. Endereço eletrônico: anapaula@ufscar.br

${ }^{2}$ Universidade Federal de São Carlos, São Carlos. Endereço eletrônico: carmenpassos@gmail.com 
o contexto da pesquisa e os encaminhamentos metodológicos. Na terceira seção, analisam-se os depoimentos dos participantes da extensão, focalizando o processo que percorreram ao longo do curso, os conhecimentos mobilizados e as aprendizagens. Por último, descrevem-se as considerações finais deste artigo.

\section{Enquadramento teórico}

Diversos estudos contribuem para a discussão sobre as maneiras como o desenvolvimento das tecnologias digitais e a evolução da microeletrônica alteram - e o fazem profundamente - as formas de comunicação, as organizações e instituições, as funções e qualificações profissionais, os comportamentos, os valores e os modos de pensar tanto do indivíduo quanto da sociedade.

Kenski (2012, p.32) assessora no aprofundamento dessa discussão, ao enfatizar que a tecnologia digital "deixa de lado a estrutura vertical e hierárquica na articulação dos conhecimentos e se abre para o estabelecimento de novas relações entre conteúdos, espaços, tempos e pessoas diferentes".

Por outro lado, é imprescindível apontar que os avanços tecnológicos não garantiram, ainda, que todos tenham acesso aos mesmos recursos tecnológicos digitais. Ademais, apenas o acesso a esses recursos não possibilita estabelecer as novas relações pontuadas por Kenski (2012). A qualidade da interação sujeito-recurso/ferramenta é fundamental, uma vez que não é a ferramenta que possibilita aprendizagens, pois estas são originadas pelo uso que se faz dos recursos.

Como destaca Almeida (2001, p.1), a inserção na "sociedade da informação não quer dizer apenas ter acesso à tecnologia de informação e comunicação (TIC), mas principalmente saber utilizar essa tecnologia para a busca e a seleção de informações que permitam a cada pessoa resolver os problemas do cotidiano".

O uso da tecnologia digital exige práticas específicas de leitura e escrita, implica no domínio de competências técnicas dos recursos e na criticidade desse uso. Podemos fazer um paralelo com Soares (2002, p.151), que define letramento digital como "certo estado ou 
condição que adquirem os que se apropriam da nova tecnologia digital e exercem práticas de leitura e de escrita na tela diferentes do estado ou condição - do letramento - dos que exercem práticas de leitura e de escrita no papel". Assim, ela conclui que a tela, ao se configurar como espaço de leitura e escrita, possibilita "novos processos cognitivos, novas formas de conhecimento, novas maneiras de ler e de escrever" (SOARES, 2002, p.151).

Considerando que os recursos tecnológicos digitais são bens culturais, ressalta-se que a escola não pode fechar suas portas a essa tecnologia e precisa superar a ideia de modismo. Todos têm direito de aprender a ler as "novas" mídias - afinal, "estar conectado, saber ler, participar do mundo digital e da rede de comunicação, são condições prévias e alimentadoras da liberdade - e por ela alimentadas" (ALMEIDA; SILVA, 2011, p.8), são condições para o desenvolvimento de uma leitura crítica da cultura digital.

Contudo, a incorporação da tecnologia digital às práticas pedagógicas não se concretiza com facilidade. Observa-se que, em alguns casos, a ferramenta tecnológica é utilizada como modismo; em outros, apenas como um elemento motivador; ou, ainda, é usada somente na realização de atividades que podem ser feitas manualmente.

Uma perspectiva diferente das demais aponta o uso dos recursos tecnológicos em tarefas que são difíceis de serem executadas sem essas ferramentas. Afinal, conforme destaca Bittar (2010), o recurso tecnológico não pode ser utilizado sem a exploração de suas potencialidades que oportunizam a aprendizagem.

Ademais, fazendo um paralelo com Penteado, Borba e Gracias (1998, p. 83), infere-se que o recurso tecnológico não substitui nem complementa o ser humano; é uma ferramenta que "reorganiza a forma como se pensa e como se age". Para os autores, as "novas" mídias influenciam o conhecimento em sua forma de expressão e produção, e isso interfere no modo como se concebe e se concretiza o currículo escolar.

Ressalta-se também que a integração entre tecnologia digital e prática pedagógica exige que o professor se movimente para uma zona de risco (BORBA; PENTEADO, 2001) desconhecida, incerta e imprevisível, que pode ser originada por problemas técnicos e por perguntas não previsíveis, referentes ao conteúdo escolar ou ao próprio aplicativo. Além disso, o computador portátil conectado à internet coloca a conectividade na mão dos estudantes e do professor, 
abrindo espaço para outros canais de comunicação (ALMEIDA; PRADO, 2008).

Infere-se, então, que o uso efetivo das ferramentas tecnológicas na escola exige determinados conhecimentos e implica, de certa forma, em algumas mudanças na configuração no trabalho docente.

Estabelecendo um paralelo com as ideias de Shulman (2004) sobre a Base de Conhecimento para ensinar, vale ressaltar que saber utilizar os recursos tecnológicos engloba dominar o conteúdo específico da matéria ${ }^{3}$ e também compreender e saber utilizar os diferentes modos de representação de um conceito e/ou ideia; considerar as maneiras como os alunos aprendem os conteúdos e seus conhecimentos prévios acerca deles; e conhecer os aspectos que facilitam ou dificultam a compreensão de determinado conteúdo - esses conhecimentos englobam a categoria do Conhecimento Pedagógico do Conteúdo.

Baseando-se nos pressupostos teóricos de Shulman sobre a Base de Conhecimento, Mishra e Koehler (2006) integram a essa teoria o Conhecimento Tecnológico, propondo as seguintes categorias: a) Conhecimento Pedagógico do Conteúdo (descrito no parágrafo anterior), b) Conhecimento Tecnológico Pedagógico, c) Conhecimento Tecnológico do Conteúdo e d) Conhecimento Tecnológico e Pedagógico do Conteúdo, que resulta da união das três categorias anteriores.

De acordo com os autores, o Conhecimento Tecnológico está em constante mudança e engloba o conhecimento do professor sobre as tecnologias padrão e as digitais, as habilidades em operá-las e a capacidade de aprender e de se adaptar aos avanços tecnológicos.

Segundo Mishra e Koehler (2006), o Conhecimento Tecnológico articulado ao Pedagógico resulta em saber integrar as tecnologias com estratégias pedagógicas gerais, implica em conhecer as limitações e os potenciais da tecnologia para o processo de ensino e aprendizagem, as variações metodológicas que podem ser feitas de acordo com o recurso tecnológico e os contextos educacionais em que cada recurso é mais adequado.

\footnotetext{
3 Para Shulman (2004), é importante que os professores: saibam definir conceitos, conheçam a estrutura de determinada área de conhecimento, saibam as formas de organização dos conteúdos dentro dessa área, compreendam por que determinados conceitos são aceitos cientificamente e outros não, conheçam a importância e as relações que eles podem estabelecer entre si e com outras áreas do conhecimento, compreendam por que determinado assunto é central em uma matéria e outros são periféricos.
} 
Ademais, o professor precisa conhecer as maneiras de utilizar a tecnologia para o ensino da matéria - este é o Conhecimento Tecnológico do Conteúdo e engloba saber quais tecnologias são mais apropriadas ao ensino de determinado conteúdo.

Mishra e Koehler (2006) apontam que a articulação dos conhecimentos descritos anteriormente resulta no Conhecimento Tecnológico e Pedagógico do Conteúdo. Isto implica a necessidade de o professor dominar os três campos de conhecimento (tecnológico, pedagógico e conteúdo específico) e suas relações, sabendo quais tecnologias podem ser utilizadas no ensino de determinada matéria, considerando as diferentes representações desta e suas especificidades de aprendizagem.

Nessa discussão, é importante considerar que a apropriação, pelo professor, dos campos de conhecimento descritos não decorre simplesmente da promulgação de propostas curriculares. Ademais, sua participação em programas ou cursos de formação que simplesmente apresentam os recursos tecnológicos e sugestões de uso no ensino não é garantia de apropriação e utilização dessas ferramentas.

Segundo Bittar (2010, p.241), a integração da tecnologia na educação acontecerá "quando a tecnologia representar um instrumento importante de aprendizagem para todos, inclusive, e, sobretudo, para o professor". E isso implica que o professor tenha autonomia no uso da ferramenta tecnológica, para implementá-la quando necessário e adequadamente.

\section{$O$ contexto da pesquisa}

O curso de extensão universitária online foi ministrado por duas professoraspesquisadoras e foi alocado no Portal dos Professores da Universidade Federal de São Carlos, com o uso do Moodle. Desenvolvido ao longo de três meses, com carga horária de 60 horas, contou com a participação de 20 estudantes de Pedagogia das modalidades presencial e a distância e 05 professores dos anos iniciais. As reuniões com o grupo ocorriam quinzenalmente, eram síncronas: enquanto o grupo dos residentes na mesma cidade da Universidade se encontrava no laboratório de informática, as licenciandas da graduação a distância, em suas cidades, participavam através de chat e/ou de fórum. Ao longo da semana todos os participantes 
desenvolviam atividades coletivas e individuais no ambiente virtual de aprendizagem.

A extensão propôs um trabalho em grupo com esses participantes, coletivo e reflexivo, envolvendo diálogo, ação e reflexão compartilhada, apoio e respeito mútuo.

O estudo metanalítico de Passos et al. (2006) mostra que os grupos colaborativos podem promover a reflexão - individual e coletiva - sobre a prática docente e sobre os conhecimentos e o processo de aprendizagem dos professores e licenciandos acerca de determinado conteúdo específico, e podem configurar-se como uma fonte de apoio para enfrentar os desafios e as dificuldades da docência.

Além disso, segundo Nacarato (2006), relações estabelecidas entre os diferentes profissionais - como professores da educação básica, licenciandos e formadores - podem ser um caminho para superar a dicotomia entre teoria e prática, uma vez que esses sujeitos se unem para estudar e compartilhar saberes e experiências, e essa união provavelmente acontecerá por suas diferenças de perspectivas em relação à prática pedagógica.

Outro aspecto positivo da proposta de extensão refere-se à interação estabelecida em um curso a distância. Corrobora-se a posição de Valente (2011) acerca da importância de uma interação intensa em um curso online, pois, muitas vezes, os alunos se sentem sozinhos. Nesse cenário, a intervenção docente é um elemento imprescindível, e é fundamental estabelecer uma abordagem do tipo "estar junto virtual" (VALENTE, 2011), cujas características são: interação intensa entre professor e alunos e entre os próprios estudantes, feedbacks rápidos, atividades síncronas e assíncronas. Essa dinâmica promove a criação de uma rede de aprendizagem e de cooperação.

Nesta pesquisa, o trabalho com características de colaboração, envolvendo a interação e o diálogo constante, é elemento intrínseco à dinâmica da proposta do curso de extensão universitária, que foi desenvolvido em três etapas.

Na primeira, os participantes inicialmente elaboraram uma narrativa na qual deveriam registrar uma reflexão sobre a integração entre tecnologia digital e o ensino de matemática. Posteriormente, discutiram, por meio de um chat e de um fórum de discussão online, aspectos teórico-metodológicos da matemática e seu ensino com recursos da tecnologia informática.

$\mathrm{Na}$ segunda etapa foram analisados softwares e propostas tarefas exploratório- 
investigativas que envolviam o ensino de matemática nos anos iniciais, com o auxílio de recursos da tecnologia informática. Além disso, os participantes elaboraram situações de ensino e aprendizagem para serem desenvolvidas em salas de aula. Neste momento do curso foram propostas as seguintes atividades: 1) chat: análise de jogos eletrônicos disponíveis online, 2) fórum e produção textual reflexiva: discussão sobre o papel pedagógico do jogo, 3) fórum e chat: discussão sobre o uso do Geoplano digital, disponível online, abordando o conceito de simetria e as construções de polígonos, 4) chat: discussão sobre tratamento da informação e construção de questionário de pesquisa de opinião, realização de pesquisa e análise dos dados; 5) fórum: socialização da pesquisa de opinião; 6) chat e fórum: Explorando o GeoGebra: construção de polígonos, cálculo de área e perímetro; 7) narrativa sobre a potencialidade do GeoGebra para o ensino de geometria nos anos iniciais.

$\mathrm{Na}$ terceira etapa os participantes fizeram uma narrativa reflexiva sobre o processo formativo percorrido ao longo do curso, e o último chat englobou o encerramento da extensão.

\section{Objetivo da pesquisa e encaminhamentos metodológicos}

Este trabalho investigou, sob a ótica de alunos da Pedagogia e de professoras dos anos iniciais, as contribuições do curso de extensão universitária online para o processo de aprender a ensinar matemática. O escopo deste estudo visa analisar o desenvolvimento do processo de aprendizagem dos cursistas no decorrer do espaço formativo mencionado, investigando os conhecimentos mobilizados e suas aprendizagens. Neste trabalho, utilizam-se nomes fictícios para fazer referências aos participantes, e todos concederam autorização para a realização da pesquisa.

Esta investigação aproxima-se da estratégia de pesquisa de estudo de caso e referendase em André (2005), para quem o objetivo do estudo de caso é compreender a situação como ela é realmente, considerando o contexto no qual ela se insere. Por isso, uma das vantagens desse tipo de estudo é proporcionar uma visão aprofundada, ampla e integrada da unidade investigada, que é composta por múltiplas variáveis (ANDRÉ, 2005), e investigar a situação, tendo em conta a sua dinâmica natural e complexidade. Em razão disso, exige-se o uso de duas ou mais 
fontes de evidências para a coleta de dados e a descrição aprofundada do fenômeno. A autora também assinala que o estudo de caso possibilita uma generalização naturalística. A partir da leitura da descrição densa do caso, do contexto, dos sujeitos e das relações que esses elementos estabelecem, o leitor indagará e decidirá se as interpretações, as ideias, as hipóteses apresentadas no estudo podem ser aplicadas à sua situação de interesse. Além disso, o estudo de caso pode revelar pistas que possibilitem o aprofundamento ou a realização de estudos futuros.

Considerando as características e os pressupostos apresentados sobre o estudo de caso, optou-se por utilizar essa abordagem metodológica - o curso de extensão foi o caso analisado e os participantes os elementos que o compõem. O interesse pelo particular está presente, e as especificidades do processo investigado se referem ao fato de que as aprendizagens proporcionadas pelo curso ocorrem em um contexto de formação com uma dinâmica e características específicas. Além disso, possivelmente as aprendizagens não são iguais para todos os participantes.

Para tanto, foram utilizadas múltiplas fontes de coleta de dados: narrativas reflexivas elaboradas pelos participantes no início e no final do curso, registros dos Fóruns de Discussão e dos diálogos ocorridos nos Chats e planos de aula elaborados pelos participantes.

\section{Concepções manifestas, indícios de mudanças e aprendizagens: a tecnologia informática nas} aulas de matemática

$\mathrm{Na}$ análise dos dados foi possível identificar algumas concepções dos participantes, seus conhecimentos mobilizados ao longo do curso, indícios de mudança de concepções e algumas aprendizagens relacionadas aos elementos da Base de Conhecimento para a docência, integrando o componente do Conhecimento Tecnológico. Nesta seção apresentam-se os dados e as discussões acerca desses elementos.

Ao analisar as primeiras narrativas elaboradas pelos cursistas, verificou-se que a maioria justificou que as tecnologias digitais precisam estar presentes nas escolas em razão de os avanços tecnológicos acontecerem rapidamente e ser necessário que todos os acompanhem. Constatouse também que o uso dos recursos tecnológicos, como forma de motivar os alunos e despertar 
o interesse em estudar, foi uma forte ideia presente nas narrativas dos cursistas.

Por outro lado, ao longo do curso, a partir dos diálogos e dos estudos teóricos, os participantes apresentaram outras ideias para justificar o uso pedagógico da tecnologia. Portanto, identificaram-se indícios de mudanças das concepções iniciais.

Uma das perspectivas reveladas nos diálogos expõe indícios de mudança: considerar que um software nas aulas de matemática pode propiciar que o aluno analise determinado conteúdo e, consequentemente, se aproprie dele.

Amanda e Fernanda, por exemplo, destacaram que apenas compreenderam o conceito de simetria ao participar do chat no qual elaboraram um mosaico simétrico no Paint Brush e depois dialogaram sobre as imagens criadas pelos colegas. Consideraram também que os alunos irão aprender esse conteúdo ao se envolverem em um processo semelhante: desenhar as figuras, pensar e dialogar com o outro sobre elas. Os trechos dos depoimentos a seguir ilustram essa perspectiva.

[...] só após fazermos nossos mosaicos é que as coisas se clarearam. Portanto, com o auxílio do software e as intervenções do professor, o processo de ensinoaprendizagem fica facilitado com as várias possibilidades que se apresentam, como, por exemplo, a utilização do Paint Brush para desenvolver uma figura simétrica a outra figura a partir do eixo de simetria. (Amanda - Chat - At. 3)

Fez toda a diferença praticarmos no Paint Brush o conceito de simetria. Pelo menos para mim, o entendimento do assunto foi bem melhor. $O$ diferencial está justamente em "colocar a mão na massa", neste caso, no computador. (Fernanda - Chat - At. 3)

Em outra circunstância, ao analisar duas situações de ensino sobre a construção e a interpretação de gráficos apresentadas em outro Chat, Joana enfatizou que o uso do computador possibilita a experimentação, uma vez que os dados informados podem ser alterados rapidamente, e os alunos podem fazer outras análises, articulando-as com as anteriores. Nas palavras da cursista:

Alterações nos valores afetam os gráficos dinamicamente, $e$ os alunos conseguem visualizar rapidamente o resultado. A criança pode perceber os erros, se autocorrigir. Se esta atividade tivesse sido elaborada no papel, os 
alunos teriam mais dificuldade em diferenciar o 3 do 30, por exemplo. (JoanaChat - At. 6)

Juliana e Adriana consideraram que essa proposta de Joana explora a potencialidade do computador e vai além de sua subutilização.

Também o comentário de Amanda se relaciona com a proposição de superar a subutilização do recurso tecnológico. Ao retomar uma das análises de Barros e Oliveira (2010) sobre o videojogo Lego Digital Designer - jogo que possibilita a manipulação e montagem de peças de Lego virtuais -, Amanda destacou que neste caso a tecnologia possibilita que o jogador faça algo que não conseguiria fazer facilmente com o bloco Lego real, pois, para ela, no videojogo o usuário "consegue visualizar de forma mais clara os movimentos realizados, facilitando assim a compreensão e aprendizagem" (Amanda - Fórum - At. 7).

Analisando os comentários das cursistas, pode-se fazer um paralelo com as ideias de Gravina e Basso (2012), que enfatizam que as ferramentas interativas postas pela tecnologia digital agregam sistemas dinâmicos de representação, que podem servir para externar, consolidar e comunicar a matemática ou para dar sustentação aos processos cognitivos que produzem o conhecimento matemático. Nessa dinâmica, os alunos fazem "experimentos de pensamento".

Infere-se que os depoimentos das cursistas com relação à produção de um mosaico simétrico no Paint Brush, à construção e à exploração de gráficos no Excel e ao uso do jogo Lego Digital Designer expressam a perspectiva de que o uso que se pode fazer desses recursos possibilita que os alunos façam "experimentos de pensamento", e, nesse cenário, a visualização é fundamental.

Outro ponto de vista revelado nos diálogos se refere ao fato de os cursistas considerarem que os jogos eletrônicos podem ser abordados em uma perspectiva de resolução de problemas, o que possibilita a interação entre alunos, alunos-máquina e alunos-professor.

É importante apontar que essa possiblidade da interação é enfatizada por Barros e Oliveira (2010), que verificaram que os videojogos não isolaram as crianças da pré-escola, pois elas se ajudavam mutuamente, propondo soluções para as tarefas postas.

Nesse sentido, segundo Vitória, Luciana e Márcia, o desafio propiciado pelo jogo é Periódico Horizontes - USF - Itatiba, SP-Brasil - e019001 
fundamental para que o aluno se coloque em movimento, realize a atividade proposta e, nessa dinâmica, aprenda os conteúdos envolvidos. Os depoimentos a seguir exemplificam essas considerações:

O uso dessa ferramenta incentiva a colaboração entre as crianças, que, juntas, são capazes de solucionar problemas existentes. (Vitória - Fórum - At. 7)

Os videojogos possibilitam experiências e tarefas desafiadoras, que induzem a compreensão dos processos matemáticos envolvidos. (Luciana - Fórum - At. 7)

O jogo pode servir como ferramenta para o desenvolvimento da capacidade de abstração da criança, pois, a partir dele, esse desenvolvimento se acentua juntamente com a capacidade de reflexão, de análise de possibilidades, bem como de estratégias para resolução de problemas. (Márcia - Fórum - At. 3)

Na perspectiva de Fábio, as situações problema geradas pelo jogo eletrônico possibilitam a prática do trabalho coletivo. Ele considerou, ainda, que a interação social possibilita que a criança pense sobre a matemática, questione as situações e busque estratégias para resolvê-las. Em suas palavras:

As autoras [BARROS; OLIVEIRA, 2010] apontam que as interações sociais fazem emergir conflitos cognitivos importantes no desenvolvimento cognitivo das crianças. Essa relação com a matemática é necessária [...]. É importante no aprendizado dos alunos que eles possam pensar, duvidar e repensar qualquer ideia que Ihes seja indagada [...]. (Fábio - Fórum - At. 7)

Especificamente sobre a interação possibilitada pelo uso de jogos eletrônicos nas aulas, Rosa e Lívia enfatizaram que o jogo eletrônico possibilita um diálogo intenso entre os alunos e o próprio jogo. Para Joana essa interação propicia o desenvolvimento de um ambiente de comunicação matemática. Segue trecho dos depoimentos dessas participantes:

[...] a interação é um dos fatores essenciais do jogo pedagógico, além das regras, objetivo, feedbacks, conflito e representação. (Rosa - Fórum - At. 7)

Outro aspecto interessante na questão da utilização dos jogos se dá com relação à interação que o jogo proporciona. [...] O diálogo, a discussão são ações facilitadoras no processo ensino-aprendizagem. (Lívia - Fórum - At. 7) 
Um parágrafo do texto que me chamou a atenção e que vai ao encontro a tudo o que discutimos ao longo do curso é a importância da comunicação e do diálogo no processo de aprendizagem. Nesse momento, a atuação do professor é muito importante para fazer a mediação pedagógica. (Joana - Fórum - At. 7)

Um dos elementos presentes nos depoimentos desses cursistas é o destaque para o fato de as problematizações originadas pelo jogo eletrônico poderem levar o aluno a analisar seu raciocínio, as possibilidades de jogadas e as estratégias, tanto individual quanto coletivamente. Isso envolve o aluno em um processo de argumentação e verificação e propicia o desenvolvimento do pensamento abstrato. Ademais, Barros e Oliveira (2010) constataram que o alto nível de interação teve como consequência uma dinâmica produtiva para a aprendizagem e proporcionou que os estudantes ampliassem seus repertórios de estratégias, as quais poderão ser utilizadas em outras situações.

Analisando o exposto, constata-se que esses participantes mobilizaram ideias relativas ao Conhecimento Tecnológico e Pedagógico do Conteúdo. Em seus depoimentos se identifica a integração desses três componentes-chave, isto é, a articulação entre o ensino da Matemática, a partir de estratégias de ensino (resolução de problemas, por exemplo) e suas potencialidades, e o uso apropriado dos recursos tecnológicos considerando o processo de aprendizagem do conteúdo específico, como, por exemplo, a noção de simetria, construção e análise de gráficos, a noção espacial (transformações geométricas, especificamente translação e rotação) e a classificação de figuras geométricas.

Outra discussão no decorrer das atividades do curso de extensão envolve uma consideração concernente ao Conhecimento Tecnológico Pedagógico: a ampliação do olhar dos cursistas acerca da necessidade de o professor analisar criticamente um recurso tecnológico. Com efeito, houve essa ampliação do olhar, uma vez que, no início do curso, muitos participantes concebiam que qualquer forma de uso da tecnologia informática era adequada, pois consideravam que ela, por si só, era atrativa ao aluno.

Entretanto, o chat em que houve a análise de duas propostas de uso do computador para a interpretação de gráficos foi um dos momentos relevantes para a ampliação desse olhar. Na proposta da professora $\mathrm{X}$, o gráfico foi disponibilizado pronto aos alunos no Word, com questões 
previamente elaboradas, a serem respondidas oralmente pelas crianças. Diferentemente, o professor $Y$ propôs a construção de um gráfico pelos alunos no Excel a partir de uma tabela e problematizou essa construção.

No início do chat, muitos cursistas elogiaram as duas atividades, afirmando que ambas possibilitaram que os estudantes interpretassem as informações contidas nos gráficos. Por outro lado, Jéssica indicou que na proposta da professora $\mathrm{X}$ a tecnologia foi subutilizada, pois, para ela, "o computador possibilita várias outras formas de trabalhar com estes conteúdos".

A partir do comentário de Jéssica, as professoras-pesquisadoras questionaram qual seria a diferença entre a proposta de trabalho da professora $\mathrm{X}$ e uma análise de gráficos em um livro didático, e retomaram os exemplos apresentados no vídeo, sugerindo novamente a análise da proposta do professor Y. Ressaltaram que nessa proposta, quando toda turma está "construindo" um gráfico a partir de uma mesma tabela, todos os gráficos devem ficar iguais; caso contrário, os alunos notarão a diferença e deverão procurar o equívoco.

Nessa discussão, alguns cursistas apontaram que o professor $Y$ fez melhor uso do recurso tecnológico. Outros questionaram se efetivamente a proposta da professora $\mathrm{X}$ potencializou $\mathrm{O}$ uso do computador. Assinalaram, então, que nem sempre é preciso utilizar o computador nas aulas e que, dependendo da forma como esse recurso for usado, ele pode deixar de lado o conteúdo. Os trechos dos seguintes depoimentos exemplificam essas considerações:

No exemplo de $X$ o interesse inicial estará atrelado à novidade do computador. E não ao estudo da matemática. (Joana - Chat - At. 6)

Não há necessidade de utilizarmos o computador quando poderíamos não usálo, como fez a professora $X$ do vídeo. (Vitória - Chat - At. 6)

Se não houver uma perspectiva, uma intenção, usaremos o computador apenas para facilitar algo ou então porque este recurso vai tornar a aula mais interessante. (Fernanda - Chat - At. 6)

Ao elaborar a narrativa final, Fernanda retomou a importância desse momento de problematização feito no chat: 
gráficos, foi o que mais me chamou a atenção e me fez refletir, até mesmo para a construção do plano de aula. (Fernanda - narrativa)

O planejamento das aulas, englobando discussão em grupo, feedback das professoraspesquisadoras e revisão do plano, foi outro momento importante para os participantes perceberem que a escolha de um recurso tecnológico precisa estar atrelada com os objetivos de aprendizagem e que o uso do recurso vai além de um fim em si mesmo. Nesse momento, as participantes se mobilizaram para aprender conhecimentos presentes na categoria Conhecimento Tecnológico e Pedagógico do Conteúdo.

Analisando as primeiras versões dos planos, verificou-se que alguns grupos propuseram o uso do recurso tecnológico como um apêndice. Sendo assim, buscou-se orientar os participantes a refletir sobre os planos elaborados, a experimentar e a analisar as situações propostas, com o intuito de que verificassem que, em alguns casos, os problemas não propiciavam de fato a investigação por parte do aluno e sua resolução não dependia do uso do recurso tecnológico indicado; e, em outro caso, os jogos eletrônicos selecionados visavam somente ao treino das operações de adição e de subtração.

Nessas situações, os participantes reelaboraram o planejamento e conseguiram propor atividades, de forma a integrar conteúdos e recurso tecnológico.

Na narrativa produzida no final do curso, alguns participantes indicaram que o processo de planejar as aulas foi fundamental para se pensar em maneiras de utilizar a tecnologia, de forma que não fosse um apêndice. Como indicam os seguintes depoimentos:

Posso dizer que o momento decisivo desta mudança de concepção [perceber que a tecnologia não é simplesmente um apêndice da aula] se deu no momento de elaboração do plano de aula, foi o fazer e refazer do plano que verifiquei as possibilidades de inserção de um software na elaboração de uma aula, [...] foi o ponto alto da minha aprendizagem, buscar, analisar, refletir e elaborar fizeram com que todo o curso fizesse sentido. (Mirian - narrativa final)

[Sobre o processo de planejamento, englobando o feedback, e a socialização dos planos] me permitiu conhecer novas tecnologias educacionais e aprender diferentes estratégias pedagógicas que podem ser utilizadas para abordar conceitos matemáticos com o apoio das Tecnologias. (Jéssica - narrativa final) 
[A partir das intervenções da professora na elaboração do plano de aula] vimos que não podemos deixar de destacar que a tecnologia a ser utilizada precisa ter o propósito em atingir o objetivo proposto pelo professor ao elaborar seu plano de aula. (Rosa - narrativa final)

Além dessas constatações, nas narrativas elaboradas ao final da extensão, outros participantes relataram que com o curso compreenderam a necessidade de elaborar situações de ensino e de aprendizagem que não subutilizem o recurso tecnológico. Essa perspectiva pode ser observada nos relatos a seguir:

[Aprendi a] importância de utilizarmos os jogos ou as tecnologias de maneira contextualizada, trazendo problematizações sobre o tema, pois se este tipo de ação não é pensada, o computador ou outra ferramenta pode ser utilizada somente como uma maneira de substituir o lápis e o papel. (Vitória - narrativa final)

Vimos o uso desnecessário da tecnologia digital, especialmente quando ela é só para substituir lousa e giz, papel e lápis, livro didático. Vimos que a tecnologia deve ser usada para auxiliar e melhorar o processo de ensino-aprendizagem, não apenas para tentar torná-lo mais atraente (o que não é totalmente inútil) apenas por dizer que a usa. (Adriana - narrativa final)

Desconstruir a visão de inserção da tecnologia enquanto um ponto de apoio, um apêndice, e transferir o mesmo para o lugar de uma ferramenta que estrutura e permeia todo processo de ensino aprendizagem. (Miriam - narrativa final)

Para trabalhar com novos conceitos através de ferramentas tecnológicas, os participantes precisaram de novas abordagens na construção de sua metodologia de ensino, acionando assim o Conhecimento Tecnológico e Pedagógico do Conteúdo.

Outros cursistas declararam, nas narrativas, terem aprendido que o recurso tecnológico pode estar articulado com a proposta de ensino por meio da resolução de problemas.

Rosa, por exemplo, aprendeu que um trabalho na perspectiva da resolução de problemas precisa ter como pano de fundo a possibilidade de haver diferentes estratégias para a resolução e que essas podem ser compartilhadas. Nesse sentido, para Rosa, a tecnologia pode ser articulada com essa proposta, propiciando fazer uma matemática: "[...] de forma investigativa e desafiadora. Logo, o jogo pelo jogo fica descartado, pois esse nos remete a mera atividade de 
treino e nos tira a possibilidade de inovação de estratégias múltiplas" (Rosa - narrativa final).

Valéria relatou ter aprendido que a tecnologia deve ser uma ferramenta para o ensino da matemática em diferentes momentos da aula, como na explicação de um conteúdo e/ou ao propor a resolução de problemas. Mas concebe que não é o único recurso a ser utilizado: "[A tecnologia] é um meio, uma ferramenta e que deve ser utilizada, mas não ser apenas única. Ela deve ser utilizada nos momentos de explicação, de construção e de elaboração de resoluções para determinados problemas" (Valéria - narrativa final).

Especificamente sobre o jogo eletrônico, Valéria também apontou que aprendeu que o uso pedagógico do jogo no ensino não se limita ao jogo pelo jogo. E que o bom planejamento do professor é essencial para superar a ideia de que simplesmente colocar o aluno diante de uma máquina fará com que ele aprenda. Em suas palavras:

Importante ressaltar que a utilização dos jogos é para melhor compreensão do conteúdo. Não é jogar por jogar. [...] Daí a importância do planejamento bem feito para aliar todas estas questões [...]. O professor deve ficar atento ao fato de que o jogo não vai ensinar o conteúdo em si aos seus alunos. (Valéria narrativa final)

Jéssica, por sua vez, declarou que, ao longo da extensão, percebeu que a tecnologia pode ser utilizada "principalmente diante de conceitos considerados complexos pelos alunos, apoiar as estratégias pedagógicas que permitam a esses alunos se desenvolverem e se apropriarem de um determinado conhecimento", ou seja, ela destacou uma perspectiva que busca superar propostas que visam simplesmente à aplicação direta do conteúdo ou ao treino de habilidades.

Para Luciana, o uso da tecnologia nas aulas deve apresentar um elemento de mudança. Em suas palavras:

Pude perceber que não basta apenas usar o laboratório e deixar os alunos à sua própria vontade, pois, se não estabelecer objetivos e não interferir de forma a acrescentar algo à aula tradicional lousa/giz, usar laboratório deixa de ser uma inovação e se perde a oportunidade de evoluir. (Luciana - narrativa final)

Os depoimentos dos cursistas mostram quão necessário é que o professor saiba escolher 
e propor o uso de um software de acordo com os objetivos da aula, e não de maneira inversa; e é imprescindível que os cursos de formação mobilizem os futuros professores e professores em exercício para essas análises. Afinal, segundo Bittar (2010), o uso da tecnologia como um apêndice em nada contribui para a aprendizagem dos conteúdos. A autora considera que a tecnologia seja "como mais um instrumento de auxílio a um ensino em que o próprio aluno constrói seu conhecimento" (BITTAR, 2010, p.240). E completa, ao afirmar que, para que essa potencialidade do software seja de fato concretizada, o professor precisa conhecer as possibilidades de ferramentas do software e suas potencialidades pedagógicas e, assim, possibilitar que o aluno se movimente para o processo de análise das estratégias utilizadas.

Nesse cenário, é positivo constatar que, nas discussões realizadas em todas as atividades propostas no curso, estiveram presentes considerações sobre a atuação docente; e perceber o quão importante é o papel do professor - reflexões estas que englobam o Conhecimento Tecnológico Pedagógico. Nesse sentido, muitos cursistas enfatizaram que o uso desses recursos não pode ser feito sem planejamento, que o professor precisa saber adequar a tecnologia à proposta de ensino, visando à aprendizagem da matemática, e, para tanto, é fundamental dominar o conteúdo específico e saber utilizar o recurso tecnológico escolhido.

O depoimento de Adriana ilustra essas considerações:

[...] o papel desempenhado pelo educador é fundamental [...] para utilizar as tecnologias de maneira significativa, o professor deve ter um domínio ainda maior sobre o conteúdo e um trabalho efetivo de pesquisa para que o melhor recurso seja o escolhido e para que haja, de fato, uma proposta pedagógica ao se escolher um software. (Adriana - Fórum - Atividade 7)

Rosa, concordando com Adriana, retomou a discussão do chat - atividade 6 - e afirmou que "no último chat que tivemos ficou claro que nem sempre a escolha da tecnologia é o melhor recurso para um determinado conteúdo" (Rosa - Fórum - Atividade 7).

Sobre o trabalho intencional do professor, Mirian destacou que

[...] há inúmeros exemplos de projetos que incluem softwares para o desenvolvimento de determinados conteúdos; vimos que eles são sempre frutos de planejamento, estudo e parcerias. Assim, para fazer uso deste recurso o 
docente deve estar preparado e disposto a fazer de sua aula algo realmente significativo aos educandos, que contribuam de fato para a construção $e$ problematização dos conteúdos e que se traduza em novas formas de aprender, não apenas transferindo o que é feito em sala de aula para a sala de informática. [...] ficou ainda mais claro a importância de alinhar a tecnologia escolhida aos objetivos pedagógicos. (Mirian - narrativa final)

Ao elaborarem a narrativa reflexiva, Luciana e Rosa também ressaltaram a importância do olhar crítico e do uso intencional da ferramenta tecnológica. De maneira semelhante, Fábio, ao elencar suas aprendizagens, discute o uso intencional dos recursos tecnológicos para o ensino da matemática e indica que um aspecto importante da potencialidade de um recurso é o uso que o professor faz dele. Segue excerto da narrativa de Fábio:

Destaco aqui a reflexão que mais moldei neste curso e levarei para minha prática, de que o uso da tecnologia das aulas de matemática não pode ser feito sem considerar o seu contexto pedagógico de uso desta tecnologia. [...] um software matemático só pode ser tido como bom ou ruim dependendo do contexto e do modo como ele será - está sendo - utilizado. Então, para ser capaz de qualificar o uso da tecnologia em sala de aula é necessário ter muito clara a abordagem educacional a partir da qual ela será utilizada e qual o papel do jogo ou software nesse contexto. (Fábio - narrativa final)

Ao analisar outros depoimentos, ficou clara a perspectiva da maioria dos cursistas de que o computador não substitui o professor.

Mirian pondera que o fato de o computador possibilitar o desenvolvimento da autonomia do aluno não coloca o professor ocupando um papel secundário no processo, pois suas decisões e ações englobam "desde o momento de propor as atividades pedagógicas, com intencionalidade educacional clara, até o momento de mediar e verificar se a atividade está atingindo os objetivos desejados [...]" (Mirian - Fórum - Atividade 7).

Segundo Adriana, o professor deve orientar o aluno a selecionar, organizar e analisar as informações da internet. Para Lívia, a tecnologia é uma ferramenta que auxilia no processo de aprendizagem e por isso não será substitutivo de outras ferramentas.

Os cursistas também apontaram que o computador não pode ser utilizado como um fim em si mesmo. 
Mirian declarou que o software deve ser utilizado como um recurso a favor da aprendizagem e que o ensino não deve ser subordinado ao aplicativo. Juliana, concordando com Mirian, afirmou que o uso do computador nas aulas de matemática não significa que seja "uma aula de informática simplesmente, mas o professor é importantíssimo como mediador entre o conhecimento, o aluno e o computador" (Juliana - Fórum - At. 7). Esse apontamento de Juliana é importante, pois mostra que o computador, em uma perspectiva pedagógica do ensino de matemática, não pode ser visto na escola como o objeto de estudo, isto é, como o conteúdo a ser ensinado, que envolve, por exemplo, os elementos constituintes do computador e seu funcionamento.

Continuando o diálogo, Fábio assinalou que o computador, por si só, não gera aprendizagem, ele é um instrumento que a propicia. Em suas palavras, os recursos tecnológicos "não fazem 'a mágica acontecer', são apenas instrumentos" (Fábio - Fórum - At. 7).

Esses apontamentos dos cursistas sobre a atuação e o papel docente são importantes, uma vez que são imprescindíveis para que se explorem as reais potencialidades dos recursos tecnológicos, visando à aprendizagem matemática.

Nesse cenário, salienta-se o proposto por Lins (2009), quando esta afirma que o software utilizado pelo professor é constituído por ele e não está conectado apenas ao currículo escolar, mas ao que o docente vê nele. Então, pode-se afirmar que não existe "o Excel", "o Paint Brush", existe "um Excel", "um Paint Brush" - afinal, para a autora, o software não fala por si próprio; o professor fala pelo software, que precisa ser explicitado e elucidado.

Portanto, destaca-se que o professor é quem irá definir o objetivo do uso do software a partir do planejamento das situações de ensino e aprendizagem. Por isso, pode-se inferir que um mesmo software pode ser utilizado para a construção de um conceito novo para os alunos ou para a aplicação de um conceito já aprendido. Sendo assim, é importante que o professor tenha clareza da forma como as tecnologias podem ser úteis ao seu trabalho e como podem transformar suas atividades, abrindo possibilidades de outras formas de interação.

Os dados deste estudo revelam o colocar-se em atividade das participantes da extensão nos momentos de estudos, discussões e elaborações dos planos de aula. Na trajetória percorrida pelos cursistas, eles se colocaram como protagonistas de suas aprendizagens, ao estudar, 
questionar, experimentar e dialogar, e assim aprenderam conhecimentos fundamentais para o exercício da docência.

A partir dessas considerações infere-se que o curso de extensão propiciou experiências educativas, pois possibilitou que os participantes se colocassem em movimento, contribuiu para a aprendizagem da docência, ocasionou a compreensão do uso pedagógico dos recursos tecnológicos e das formas de representar alguns conteúdos específicos aos alunos por meio desses recursos.

Dando continuidade às análises aqui expostas, apresenta-se um elemento que propicia a aprendizagem docente e esteve presente no curso de extensão: o dialogar com o outro. Destacase que os próprios cursistas constataram os pontos positivos do trabalho com o outro.

Alguns deles afirmaram que o diálogo possibilitou aprender com as perspectivas e com os relatos de experiência do outro, aprofundando as ideias debatidas nos chats e nos fóruns e ampliando o repertório de conhecimentos sobre estratégias de ensino.

Joana, por exemplo, destacou que a elaboração do plano de aula foi "uma possibilidade de trocar informações e construir algo coletivamente" (Joana - narrativa final). Para Rosa, "o trabalho em equipe - elaboração do plano - possibilitou contar com o olhar de cada um enxergando novas maneiras de ensinar e aprender matemática" (Rosa - narrativa final).

Além disso, para Joana a socialização dos planos elaborados pelos grupos ampliou seu olhar sobre "as possibilidades de maneiras interessantes de trabalharmos com os nossos alunos" (Joana - narrativa final). Vitória fez destaque semelhante sobre o compartilhar os planos e, além de aprender mais sobre possíveis estratégias de ensino, ela percebeu "o quanto é importante e pode ser rica a socialização de atividades e ideias entre os professores, o que, infelizmente, às vezes é tão difícil" (Vitória - narrativa final).

Além disso, esse compartilhar possibilitou que Mirian percebesse que não era a única com inseguranças e dificuldades. Em suas palavras,

[...] muitos dos integrantes também sentiam o mesmo que eu, seja em maior ou menor intensidade, porém estávamos juntos, aprendendo e debatendo sobre formas de melhorar e tornar nossa prática algo mais significativo para os educandos, mostrar a eles que a matemática não é algo impossivel. (Mirian narrativa final)

Periódico Horizontes - USF - Itatiba, SP-Brasil - e019001 
Os licenciandos também assinalaram que o diálogo com as professoras em exercício possibilitou certo contato com a prática docente. Os excertos das narrativas de Rosa e de Fábio exemplificam essa contribuição do diálogo:

Discussões enriquecidas com a participação de vários colegas que já atuam na área educacional e que puderam, com suas experiências, nos fornecer relatos, ideias e atitudes que poderão ser colocadas em prática no futuro exercício da docência. (Rosa - narrativa final)

Pude experimentar a troca de conhecimentos com alunos de variadas idades e variadas regiões, que retratavam suas experiências em salas de aula ou projetos trabalhados. Essa partilha de experiências e conhecimentos fora muito boa para minha compreensão da profissão da qual escolhi. (Fábio - narrativa final)

Ademais, os participantes declararam que a comunicação constante, tanto síncrona quanto assíncrona, foi fundamental para o aprofundamento das discussões e para as orientações relativas à elaboração dos planos de aula.

Sobre a comunicação síncrona, Joana e Lívia afirmaram que a conversa em "tempo real" auxiliou e possibilitou momentos de ricas discussões.

Vitória e Rosa enfatizaram que a proximidade das professoras-pesquisadoras resultou em uma intensa interação. Em suas palavras:

Em relação ao curso como um todo, algo que gostei muito foi a proximidade das professoras e o feedback que sempre recebíamos (apesar de ser um curso " $a$ distância"). Podíamos contar com elas o tempo todo. Não ficamos sem orientação, nem auxílio. (Vitória - narrativa final)

Não podemos deixar de considerar a participação efetiva das professoras que atuaram como intermediárias na nossa aprendizagem às quais muitas vezes recorremos para nos prestar auxílio. (Rosa - narrativa final)

Os depoimentos dos participantes mostram que o curso de extensão foi concretizado a partir da intensa interação e comunicação entre todos e da devolutiva rápida dos feedbacks. É importante ressaltar que a intensidade da interação e a intervenção docente são alguns dos elementos-chave nessa proposta. Afinal, sabe-se que em um espaço formativo online as Periódico Horizontes - USF - Itatiba, SP-Brasil - e019001 
ferramentas, por si sós, não promovem a interação entre os cursistas e entre eles e o conteúdo. Além disso, não existem o "olho no olho" e os gestos (VALENTE, 2011).

Assim sendo, infere-se que o tipo de comunicação e de interação proposto no curso de extensão pôde contribuir para que os participantes fossem protagonistas de suas aprendizagens e produtores de conhecimento.

Sobre essa participação efetiva, pode-se retomar a contribuição de Alrø e Skovsmose (2006), ao afirmarem que o diálogo não é um simples ato comunicativo e que a qualidade da aprendizagem depende da qualidade da comunicação. Para os autores, "o diálogo é visto como um processo de descoberta, influenciado pelo fazer coletivo e compartilhado, não se constituindo como mero ato das pessoas se comunicarem, mas da profundidade e riqueza desse ato" (ALR Ø; SKOVSMOSE, 2006, p.29). Considera-se que essa qualidade da comunicação esteve presente ao longo desse curso de extensão.

Ademais, segundo Valente (2011), no "estar junto virtual" o docente conhece os estudantes, propõe desafios, auxiliando-os na apropriação do conhecimento. As problematizações apresentadas pelas professoras-pesquisadoras em cada atividade foram consideradas como um aspecto positivo por alguns participantes, por terem propiciado que desenvolvessem um olhar crítico para os recursos tecnológicos. Os seguintes excertos, retirados das narrativas, ilustram esse apontamento:

Era muito legal ver como elas [professoras] iam propondo reflexões e o desenvolvimento de questões e, depois de uma "chuva" de comentários, iam sistematizando os pontos abordados e tirando as dúvidas. Isso acontecia tanto nos fóruns quanto nas aulas nos chats e nos fóruns. (Vitória - narrativa final)

As professoras nos apresentavam uma ferramenta, depois que já estávamos discutindo várias formas de utilização, elas interrompiam questionando se a ferramenta era mesmo necessária e mostravam outras possibilidades, por vezes mais eficientes. Essa experiência colaborou para nossa formação crítica e reflexiva. (Jéssica - narrativa final)

As atividades que realizávamos nos chats eram desafiadoras e nos surpreendiam. Este momento de troca, de socialização de nossas experiências e sentimentos em relação às atividades foi muito rico para o aprendizado. $O$ gráfico dos sorvetes no Excel, por exemplo, e o mosaico simétrico no "paint" foram atividades muito boas para dar o pontapé inicial das próximas atividades 
e também para compartilharmos nossas dúvidas e dificuldades. (Valéria narrativa final)

Assim sendo, no cenário do curso de extensão, a postura das professoras-pesquisadoras, ao proporem questionamentos e fazerem intervenções, foi importante. Os cursistas também assumiram um papel ativo não apenas na continuidade das discussões, mas também na sistematização das aprendizagens e nas relações estabelecidas ao longo do curso.

\section{Algumas considerações}

A discussão realizada neste artigo apresentou o processo percorrido por licenciandos e professores em um curso de extensão universitária online, seus conhecimentos mobilizados e suas aprendizagens.

A análise dos dados revelou indícios de mudanças das concepções dos participantes sobre o uso da tecnologia nas aulas de Matemática, uma vez que, no início do curso, muitos participantes consideravam adequada qualquer forma de uso da tecnologia informática no ensino de matemática e que seu uso era importante em razão de estimular o interesse do aluno pelo conteúdo.

Destacam-se as seguintes aprendizagens dos participantes: os recursos tecnológicos não devem ser utilizados simplesmente como um elemento de facilitação e não possuem um fim em si mesmo; a tecnologia pode propiciar que o aluno se envolva em um processo de análise do conteúdo matemático estudado; ela é um contexto rico para se trabalhar com a resolução de problemas e possibilitar a interação entre alunos, alunos-professor e alunos-máquina. Ademais, os participantes indicaram que a ação planejada do professor e seu olhar crítico para as ferramentas tecnológicas são fundamentais para articular objetivos de aprendizagem, conteúdos e tecnologia.

A estrutura de desenvolvimento do curso o materializou-o com base no diálogo e na colaboração, propiciando uma comunicação intensa entre participantes e professoraspesquisadoras, com a valorização do outro e a disponibilidade dos cursistas para analisar e refletir sobre os comentários dos outros, buscar outras fontes de análise e reelaborar seus 
pensamentos e argumentos sobre a temática em estudo.

As conclusões deste artigo mostram a importância de eleger o diálogo e o trabalho com o outro como estratégias formativas, conectadas por momentos de estudos de referenciais sobre a articulação entre tecnologia informática e o ensino de matemática, a análise e a experimentação de softwares, assim como a análise e o planejamento de situações de ensino que envolvam o uso de recursos tecnológicos nas aulas de matemática.

Essa dinâmica pode contribuir para o desenvolvimento de um profissional que estabeleça uma postura crítica em relação aos recursos tecnológicos, tenha ciência de que os objetivos da aula não devem se subordinar a essas ferramentas e saiba articular elementos pedagógicos, tecnológicos e conteúdo matemático, centrando o uso das tecnologias na tarefa de aprender.

O curso de extensão também se configurou como uma experiência formativa para as professoras-pesquisadoras. O desenvolvimento da extensão, tendo como princípio a interação e o diálogo constante, permitiu a flexibilidade do planejamento do curso e a consideração da voz dos participantes. Isso possibilitou que as professoras-pesquisadoras ampliassem o olhar sobre a formação docente e reforçassem a ideia da importância de futuros professores e professores em exercício serem protagonistas de seu desenvolvimento profissional. Permitiu também apurar a sensibilidade das professoras-pesquisadoras para falar com o outro e valorizar seu trabalho e para analisar a trajetória formativa e as aprendizagens do outro.

Por fim, enfatiza-se que esta pesquisa mostra o quanto é imprescindível o engajamento das Instituições de Ensino Superior na busca de uma formação docente de qualidade, pois é este compromisso que possibilita a materialização de um rico espaço formativo. Não adianta ter boas intenções, se não houver o respaldo das instituições e das políticas públicas para concretizá-las.

\section{Referências}

ALMEIDA, M. E. B. Tecnologia na escola: criação de redes de conhecimento. Série Tecnologia na Escola - Programa Salto para o Futuro, Novembro, 2001. Disponível em:

<http://tvescola.mec.gov.br/images/stories/publicacoes/salto_para_o_futuro/livro_salto_tecn ologias.pdf>. Acesso em 10 de janeiro de 2018.

ALMEIDA, M. E. B.; PRADO, M. E. B. B. A formação de educadores em serviço com foco nas 
práticas escolares com o uso do laptop educacional em uma escola pública. In: SIMPÓSIO BRASILEIRO DE INFORMÁTICA NA EDUCAÇÃO, 19., 2008, Fortaleza. Anais... Fortaleza: Universidade Federal do Ceará, 2008. p.1-11.

ALMEIDA, M. E. B.; SILVA, M. G. M. Currículo, tecnologia e cultura digital: espaços e tempos de web currículo. Revista e-curriculum, São Paulo, v.7, n.1, abr. 2011. Disponível em <http://revistas.pucsp.br/index.php/curriculum> Acesso em 5 de novembro 2013.

ALR $\varnothing$, H.; SKOVSMOSE, O. Diálogo e aprendizagem em educação matemática. 2. ed. Belo Horizonte: Autêntica, 2006.

ANDRÉ, M. Estudo de caso em pesquisa e avaliação educacional. 2. ed. Brasília: Liber Livro, 2005.

BARROS, C.; OLIVEIRA, I. R. Videojogos e aprendizagens matemáticas na educação pré-escolar: um estudo de caso. Educação, Formação \& Tecnologias, v.3, n.2, p.95-113, nov. 2010.

BITTAR, M. A escolha do software educacional e a proposta pedagógica do professor. In: COSTA, N. M. L. de; BELINE, W. (Org.). Educação matemática, tecnologia e formação de professores: algumas reflexões. 1. ed. Campo Mourão: Editora FECILCAM, 2010. p.215-242.

BORBA, M. C.; PENTEADO, M. G. Informática e educação matemática. 1. ed. Belo Horizonte: Autêntica, 2001.

GRAVINA, M. A.; BASSO, M. V. A. Mídias digitais na educação matemática. In: GRAVINA, M. A. et al. (Org.). Matemática, mídias digitais e didática: tripé para formação de professores de matemáticas. 1. ed. Porto Alegre: Evangraf, 2012. p.11-36.

KENSKI, V. M. Tecnologias e ensino presencial e a distância. 9. ed. São Paulo: Papirus, 2012.

LINS, A. F. Tendências sobre o papel do usuário de tecnologia: olhando para alguns campos de estudos e para a educação matemática. In: LOPES, C. E.; NACARATO, A. M. (Org.) Educação matemática, leitura e escrita. armadilhas, utopias e realidade. 1. ed. Campinas, SP: Mercado de Letras, 2009. p.219-240. (Série Educação Matemática, v. 2).

MISHRA, P.; KOEHLER, M. J. Technological pedagogical content knowledge: a framework for teacher knowledge. Teachers College Record, v.108, n.6, p.1017-1054, 2006.

NACARATO, A. M. Professores e futuros professores compartilhando aprendizagens: dimensões colaborativas em processo de formação. In: NACARATO, A. M.; PAIVA, M. A. V. (Org.). A formação do professor que ensina matemática: perspectivas e pesquisas. 1. ed. Belo Horizonte: Autêntica, 2006. p.197-212. 
PASSOS, C. L. B. et al. Desenvolvimento profissional do professor que ensina matemática: uma meta-análise de estudos brasileiros. Quadrante, Lisboa, v.XV, n.1-2, p.193-219, 2006.

PENTEADO, M. G.; BORBA, M. C.; GRACIAS, T. S. Informática como veículo para mudança. Zetetiké, Campinas, CEMPEM, v.6, n.10, p.77-86, jul./dez. 1998.

SHULMAN, L. Those who understand: knowledge growth in teaching. In: WILSON, S. M. (Ed.). The wisdom of pratice: essays on teaching, learning and learning to teach. 1. ed. United States of America: Jossey-Bass, 2004. p.189-215.

SOARES, M. Novas práticas de leitura e escrita: letramento na cibercultura. Educação e Sociedade, Campinas, v.23, n.81, p.143-160, dez. 2002.

VALENTE, J. A. Educação a distância: criando abordagens educacionais que possibilitem a construção de conhecimento. In: ARANTES, V. A. Educação a distância. 1. ed. São Paulo: Summus, 2011. p.13-44.

Recebido em setembro de 2017.

Aprovado em novembro de 2017. 